\title{
Is Russia Rationally Developing its Small and Medium-Sized Enterprises? An Analysis of Regional Production Functions
}

\author{
Pinkovetskaia Iuliia* \\ Ginzburg Maria ${ }^{* *}$
}

\begin{abstract}
The purpose of this study was to examine if it makes sense to further stimulate the development of small and medium-sized businesses in Russia by the State. For this purpose, the authors formulated the following hypotheses: production functions can be used to explore opportunities to promote SMEs in Russia (hypothesis 1). However, if the values of degrees of factors are positive, it can be argued that SMEs development can be achieved by State measures to facilitate an increase in labour costs and investment in fixed assets of SMEs (hypothesis 2). To check formulated hypotheses we have developed production functions, which reflect dependences between SMEs turnover from investments in fixed assets and employees wage. Regression analysis was used to determine the parameters of production functions. While conducting calculations, we used the data of total observation of SMEs activities, provided by the Federal Statistical Service in 83 regions of the Russian Federation for the year 2015. Taking into consideration an important role of SMEs in Russian economy, the results of this research might help government bodies in resource distribution for particular regions and sectors of economy in these regions. From methodological point of view this research shows, that production functions might be used in Development Strategy of SMEs for the period of up to 2030, which establishes double production growth in SMEs.
\end{abstract}

Keywords: SME; production function; turnover; Cobb-Douglas function; wage

JEL Classification: C31, H5, L26, O52, R11

\footnotetext{
${ }^{*}$ Pinkovetskaia Iuliia is at Institute of Economics and Business, Ulyanovsk State University, Russia.

** Ginzburg Maria is at Institute of Economics and Entrepreneurship, Lobachevsky State University of Nizhny Novgorod, Russia.
} 


\section{Introduction}

Economists agree that entrepreneurship is one of the important drivers of sustainable economic development and growth in the current economy (Baumol, 2004; Castano et al., 2016; Grigore and Dragan, 2015; Kirilyuk, 2013). According to Doh and Kim (2014), SMEs play an important role in economic performance all around the world, providing sources for most new jobs and innovations. After having studied the works of contemporary researchers, we came to the conclusion that the issues of production functions development are studied quite extensively. For example, Afanasyev and Ponomariov (2014) describe some outcomes of the development of the production function of Cobb-Douglas type for illustration of expanded reproduction process of the Russian economy in the period from 1990 to 2003 from the point of view of the classic criteria of econometrics. Belykh and Berdukovskaja in their study (2015) list the possibilities of using production functions for forecasting. Antipov (2012) builds a production function of Russian economy. At the same time, while building the function he recommends to use indicators in constant prices and in relation to the same reference year. Principles for the development of production functions for the region were outlined in the following papers (Adamadziev and Khalilov, 2016; Baranov, 2014; Bessonov and Tsukhlo, 2002). Gafarova in her paper (2013) presents the results of the model based analysis of the Gross Regional Product of the Republic of Bashkortostan. Baranov in his paper (2014) contemplates on peculiarities of production function usage in regional studies. Adamadziev and Khalilov in their study (2016) describe production functions equations expressing the dependence of the volume of Gross Regional Product from the value of the fixed assets, the number of people employed in the economy and investment value in small, medium and large regions. Muro in his paper (2013) proved that the three-sector Cobb-Douglas GDP function with three factors must be useful for empirical studies in structural change. Balistreri et al. (2003) evaluate the Cobb-Douglas specification as a transparent starting point in simulation analysis. Koo et al. (2013) consider an optimal consumption, leisure, investment, and voluntary retirement problem for an agent with a Cobb-Douglas utility function. Using dynamic programming, they offer production functions and optimal strategies for consumption, leisure, investment, and retirement. Labini suppose that the Cobb-Douglas function can be retained 'at a first approximation', in any case, empirically it has had 'an apparent success'. He also maintains that we have to allow for technological changes and, therefore, assume a dynamic - not a static - substitution (Labini, 1995). Choi and Kim (2017) examine the effect of regional total factor productivity on local employment growth using regional panel data in Korea. Their paper introduces a dynamic panel regression model that considers the effect of lagged employment. Thus, the professional literature analysis showed, that the most commonly used production function is Cobb-Douglas production function. 


\section{Methodical Approach to Assessment of Production Functions}

Small and medium enterprises located in each of Russia's regions were considered as a research object. The current law (Federal law, 2007) has established the main criterion for classifying small and medium enterprises. This criterion is quantity of employees engaged in SMEs. Number of employees for microenterprises should not exceed 15 people, for small enterprises (without microenterprises) this figure ranges from 16 to 100 people, and for medium enterprises - from 101 to 250 people. Another criteria is the presence of state and municipal property share in the equity of the business, and revenues from sales of goods and services, as well as the carrying amount of the assets.

Taking into account the approach accepted in Russian statistics, the volume of production of small and medium enterprises characterize by the total turnover, which consists of the cost of goods of their own production and proceeds from the sale of the purchased goods.

In accordance with the recommendation of Granberg (1988), the number of factors in the production function must be small, since in this case calculations and interpretation of the results are simplified. In the research we considered investments in fixed assets and employees' wages as factors of production functions. Correlation analysis showed that these factors have the greatest impact on SMEs turnover. At the same time, there is no mutual connection (collinearity) between them. It should be noted that the investment flow provides more acceptable results compared to such factor as fixed assets. This conclusion was made in the papers (Bessonov and Tsukhlo, 2002; Gavrilenkov, 2000) on the basis of analysis using fixed assets in SMEs. Analysis showed their incomplete use. Wages of employees in SMEs represent a comprehensive indicator which considers not only the labor costs of production, but also the characteristics of a particular region (price level, employment and other socio-economic aspects). In addition, the use of employees, wages as a factor ensures identical dimension of all indicators of production functions. The identical dimension of all production function indicators, as shown in the article (Felipe and McCombie, 2012), provides high quality of the relevant models.

Based on the results of Baumol (2004), Doh and Kim (2014), Castaño et al. (2016), Vilensky (2011), Kazakova (2013), Kirilyuk (2013), Kleiner (1986), Ruzanov and Ruzanov (2015) as well as on the results of the authors' pilot studies (Ginzburg and Pinkovetskaya, 2017; Mitin et al., 2014; Pinkovetskaya, 2014; Yashina et al., 2016), we formulated the following hypothesis. We hypothesized that: production functions can be used to explore opportunities to develop SMEs in Russia (hypothesis 1). Also, we believe that: if the value of degrees of factors in functions are positive, it can be argued that SMEs development stimulation can be achieved by increasing labour costs and growth of investment in fixed assets (hypothesis 2). 
In the course of our study we have developed production functions that reflect dependence of SMEs turnover from investments in fixed assets and wages of employees. These functions were developed for sets SMEs in each of Russian region, as well as for three dimensional categories: medium enterprises, small enterprises (excluding microenterprises) and microenterprises. In our research we used spatial data characterizing the considered factors and the resulting indicators for all SMEs located in each Russia's region. This approach is caused by the following. The criteria for classifying enterprises as SMEs have changed many times in recent years. The current criteria have been used since 2008. Accounting for SMEs is carried out once a year, and the data are submitted to statistical bodies. Therefore, modeling of indicators characterizing the activities of such enterprises using time series is possible only for 8 years (from 2008 to 2015). Accordingly, the number of observations is equal to eight, which is less than the minimum acceptable value, which according to the criterion proposed by Khodasevich (2017) should be at least 16 for the two-factor function. Therefore we felt inappropriate to evaluate features, built on short-term data. In the calculations, we used the data of observation of small and medium enterprises activities presented by Federal State statistics service (2018) for 83 regions of Russia for the year 2015. Thus, the total number of observations - 83 meets the most stringent requirements for statistical data to conduct a regression analysis (Harris in his work (1985) indicated that for two-factor function, the number of observations should be not less than 52). It should be noted that spatial data allow avoiding problems that are characteristic of time series. Even the founder of the theory of production functions Douglas (1967) specified that at the same time functioning objects for one certain period are interesting to consider. Advantages of using spatial data in assessment of production functions are described in detail in the paper (Charoenrat and Harvie, 2013).

Our research included the following steps:

1. Collection and procession of initial statistical data. Formation of information arrays based on the data characterizing the sets of SMEs, located in each of Russia's regions. These arrays describe the values of SMEs turnover, flow of investment and wages for 2015.

2. Linearization of the data obtained at the first stage, which characterize independent factors and resulting variables.

3. Development of production functions using the method of least squares.

4. Assessment of quality of functions using correlation and determination coefficients, Fisher-Snedecor and Student's tests as well as corresponding significance levels.

5. Verification of the developed functions for the presence of autocorrelation, heteroscedasticity and multicollinearity, and also verification of hypothesis that errors have the normal distribution.

6. Consideration of the theoretical and practical results following the analysis of the developed production functions and opportunities of their use. 
In the research official statistics of Federal State Statistics Service on activities of small and medium enterprises in Russia for 2015 was used.

In the course of our research five production functions reflecting dependence of SMEs turnover on fixed capital investment and employees' wages in all regions of Russia have been developed. The functions constructed by the authors have the specification similar to the well-known Cobb-Douglas functions. The parameters of production functions were determined using the regression analysis methodology (Pindyck and Rubinfeld, 2013).

\section{Results}

We developed five production functions. They based on the methodology of regression analysis and on previous study (Pinkovetskaya, 2014). The following are our production functions, which reflect the dependence of the turnover of SMEs located in Russian regions, from investments in fixed assets and employees wage. The first of these functions is:

$$
y_{S M E}\left(x_{1}, x_{2}\right)=12,406 x_{1}^{0,197} x_{2}^{0,911}
$$

where $y_{S M E}$ - small and medium enterprises turnover on regions of Russia, billions of rubles; $x_{1}$ - small and medium enterprises fixed assets investments on a related region of Russia, billions of rubles; $x_{2}$-small and medium enterprises employees wage on a related region of Russia, billions of rubles.

Graphically designed function is presented in Figure 1.

Figure 1: The production function, reflecting SMEs turnover dependency from investments in fixed assets and wage of employees

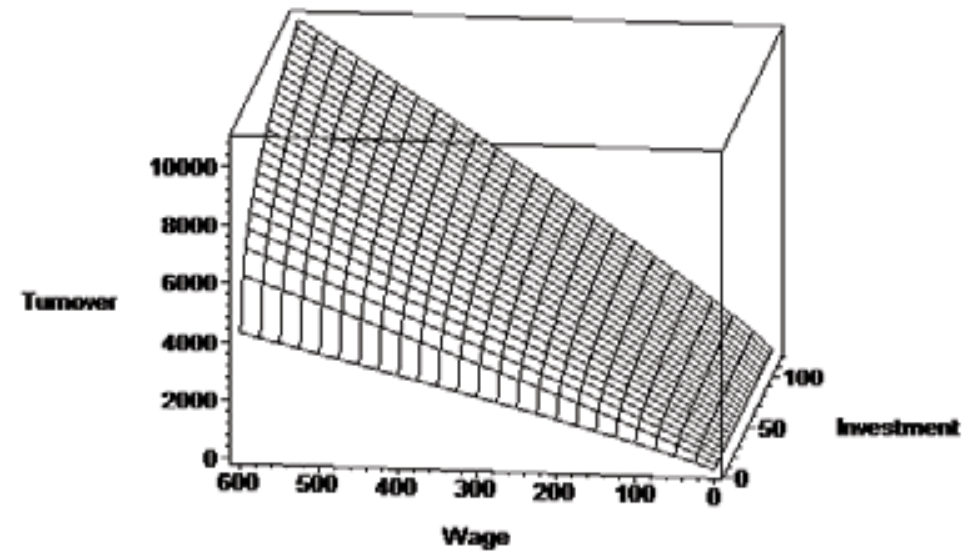

Source: Authors 
From the diagram it can be seen that growth in both wages and investment in fixed assets leads to increased turnover.

It should be noted that Russia has two subject-metropolis, these are cities of federal importance: Moscow and St. Petersburg. The number of enterprises belonging to SMEs in this cities is more than $20 \%$ of all Russian enterprises and significantly differs (298 000 respectively and 167000$)$ from the average number of such enterprises in the remaining Russian regions (27 000). Taking into consideration the significant differences of indicators on SMEs of the cities of Moscow and St. Petersburg, we have developed a production function for regions of the country, excluding data on enterprises in these cities. The function has the following form:

$$
y_{S M E w i t h o u t M S p B}\left(x_{3}, X_{4}\right)=12,811 X_{3}^{0,203} x_{4}^{0,894}
$$

where $y_{S M E \text { without } M S P B}$ - small and medium enterprises turnover on regions of Russia, excluding data on Moscow and Saint Petersburg cities, billions of rubles; $x_{3}-$ small and medium enterprises fixed assets investments on a related region of Russia, billions of rubles; $x_{4}$ - small and medium enterprises employees wage on a related region of Russia, billions of rubles.

Comparison of functions (1) and (2) showed that the parameters of these functions differ by less than 4\%. Therefore, SMEs in Moscow and Saint Petersburg are not significant differ on their activity from other cities.

$$
y_{M E}\left(x_{5}, x_{6}\right)=11,857 x_{5}^{0,106} x_{6}^{0,983}
$$

where $y_{M E}$ - medium enterprises turnover on regions of Russia, billions of rubles; $x_{5}$ - medium enterprises fixed assets investments on a related region of Russia, billions of rubles; $x_{6}$ - medium enterprises employees wage on a related region of Russia, billions of rubles.

The production function for small enterprises (without microenterprises) is as follows:

$$
y_{S E}\left(x_{7}, x_{8}\right)=11,533 x_{7}^{0,138} x_{\mathbf{8}}^{0,974}
$$

where $y_{S E}$ - small enterprises (without microenterprises) revenue on regions of Russia, billions of rubles; $x_{7}$ - small enterprises (without microenterprises) fixed assets investments on a related region of Russia, billions of rubles; $x_{8}$ - small enterprises (without microenterprises) employee's wage on a related region of Russia, billions of rubles.

The production function for microenterprises is as follows:

$$
y_{M I E}\left(x_{9}, x_{10}\right)=22,159 x_{9}^{0,217} x_{10}^{0,836}
$$


where $y_{M I E}$ - microenterprises turnover on regions of Russia, billions of rubles; $x_{9}-$ microenterprises fixed assets investments on a related region of Russia, billions of rubles; $x_{10}$ - microenterprises employees wage on a related region of Russia, billions of rubles.

Logical analysis of production functions showed that they adequately describe the regularities of the SMEs in the particular regions of the country throughout the range of the changes in the values of factors.

Table 1 presents the estimated values for checking the quality of statistics on all five production functions showed above.

Table 1: Calculated values for quality checking

\begin{tabular}{|c|c|c|c|}
\hline Function number & $\begin{array}{c}\text { The determination } \\
\text { coefficient }\end{array}$ & $\begin{array}{c}\text { The correlation } \\
\text { coefficient }\end{array}$ & $\begin{array}{c}\text { The calculated value based on the } \\
\text { criteria of the Fischer-Snedekor }\end{array}$ \\
\hline$(1)$ & 0.952 & 0.976 & 758.443 \\
\hline$(2)$ & 0.943 & 0.971 & 610.621 \\
\hline$(3)$ & 0.915 & 0.956 & 401.803 \\
\hline$(4)$ & 0.952 & 0.976 & 737.317 \\
\hline$(5)$ & 0.961 & 0.980 & 948.787 \\
\hline
\end{tabular}

Source: Authors

Table 2 shows calculated values of one of the most significant criteria for assessing the quality - Student criteria (t-test), as well as the magnitude of standard errors.

Table 2: T-test and standard errors analysis results (Source: Authors)

\begin{tabular}{|c|c|c|c|c|}
\hline \multirow{2}{*}{ Function number } & \multirow{2}{*}{ Function factor } & \multicolumn{2}{|c|}{ The calculated value of the Student-criteria } & \multirow{2}{*}{ Standard error } \\
\cline { 3 - 4 } & & 1st factor & 2nd factor & \\
\hline & 27.956 & 3.225 & 15.681 & 0.281 \\
\hline$(1)$ & 26.294 & 3.288 & 14.597 & 0.282 \\
\hline$(3)$ & 28.988 & 2.267 & 13.206 & 0.382 \\
\hline$(4)$ & 30.255 & 2.828 & 20.071 & 0.285 \\
\hline$(5)$ & 61.271 & 5.591 & 19.285 & 0.256 \\
\hline
\end{tabular}

Source: Authors

Calculated values comparison, shown in tables 1 and 2 with criteria represented in the literature shows that all production functions have high quality. Thus, coefficients of correlation are greater than 0.95 . The coefficients of determination characterize quality of the regression equation (Demidenko, 1981). The closer the coefficient of determination to 1 , the closer is the functional dependency between production volume and discussed factors. According to Draper and Smith (1998) regression model 
is successful when the coefficients of determination are greater than 0.8 . While the difference between 1 and the coefficient of determination describes the proportion of deviation in turnover caused by the influence of other factors not included in the production function. Table 1 data analysis allows us to conclude that the models from (1) to (5) explain more than $91 \%$ of dependent variables variation. Respectively for the other factors (not considered by us) accounted for not more than $9 \%$. The calculated values of statistics on all functions are much more than tabular values of the Fischer-Snedecor criteria equivalent to 3.15. The figures in table 2 show that all calculated values for t-criteria of Student-test for functions from (1) to (5) with significance level equal to 0.05 , are more than tabular values of 1.99 . Standard errors for functions are small; approximation errors for all functions are less than 5\%, that indicate a good selection of models to original data (Eliseeva, 2003). Thus, it is possible to make a conclusion on the feasibility of using production functions for the evaluation of functioning economic systems such as the complex of small and medium enterprises in the regions.

\section{Discussion}

The production functions analysis revealed several patterns typical for the entrepreneurship sector of the Russian economy. The values of degrees for both factors are positive in the functions and, consequently, an increase in one of them, even while maintaining a constant value of the second, leads to an increase in turnover of SMEs in the region. Thus, we can conclude that stimulation of the development of small and medium enterprises can be provided by increasing wage costs and growth of investment in fixed assets. This means that the hypothesis (2) was confirmed. Production functions on both factors does not reach its maximum. This is confirmed by the fact that the values of the maximum return on both factors for all functions are positive on the considered ranges of the factors values change. From this, it can be concluded that the economy of the regions of the country has not reached the saturation of SME sector production, and this sector has substantial stock for further development. Significant reserves to increase the volumes of production of goods and services there are in all regions of Russia, including the cities of Federal significance (Moscow and St. Petersburg). Estimate of such reserves can be performed using the designed production functions, that is, the hypothesis (1) was confirmed. The sum of the degree values in all production functions are more than 1, which testifies to the increasing returns to scale. That is, while simultaneously increasing both factors (investments and wages), turnover growth is faster than factors growth. For example, with the growth of both factors in function (1) for $10 \%$, turnover increases by $11.08 \%$. Turnover increases faster than both factors, that has important economic and social value. To boost SMEs turnover for regions makes sense to provide simultaneous growth 
both of these factors. That will provide increasing returns to scale. It should be noted that for the Russian regions with working population surplus (for example, republics of the Northern Caucasus) the basic direction of development of entrepreneurship is associated with increased employment of residents and the creation of family businesses. In regions, where is a shortage of potential employees (Siberia and Far East) increasing SMEs turnover can be based on the stimulation of investment activity. Cross derivates of production functions for each of two factors are positive for all values of range of factors. Therefore one factor increase improves the conditions for the use of another factor. Thus, the growth of wages of employees improves return on equity. Conversely, increase of investment increases the use of wages. Elasticity of turnover on investment in fixed assets is less than turnover elasticity on wages. It suggests that extensive turnover growth is typical for those production functions. Second derivatives of all isoquants are positive. The level of their convexity decrease with SMEs revenue grown. Which indicates an increase in the elasticity of factors substitution: with the SMEs revenue growth increase abilities to replace one factor to another. Wage factor in functions (1)-(5) affects the turnover of small and medium enterprises in a greater degree than factor of investments in fixed assets. It seems logical, since most of such enterprises are characterized by relatively weak technical equipment.

\section{Conclusion}

Analysis of our production functions showed that they have high quality for all the considered criteria. The analysis also proved that these functions approximate good the empirical statistical data throughout the interval values change each of the factors. Obtained functions are not overloaded by secondary factors. Results, obtained during the study, have practical importance for authorities exercising regulation and assist entrepreneurship. Research results can be applied to monitoring of entrepreneurial climate, assessing the level of efficiency in the use of factors considered in specific regions. Developed formulas can be used to determine investment necessity and human resources, the plans formation, programs and strategies for further development of small and medium enterprises in Russian regions. The methodology used in the study can be successfully applied in countries with significant (16 and over) number of territorial (administrative) units. In our further research, we plan to continue to study the level of investments in fixed assets and wages of employees in the Russian regions and selected municipalities, to have an opportunity to make forecasts for the development of SMEs.

The results of this research might be useful when defining potential possibilities of SMEs participation in Russian regions economic life, and in economic life of the country in general. The results, achieved by the authors of this research, might be 
used by the bodies of power for SMEs policy development in separate regions. Federal and regional authorities must concentrate particular attention on the certain sectors of economy, as well as the certain regions of the country, where SMEs were not sufficiently developed. Taking into consideration an important role of SMEs in Russian economy, the results of this research might help government authorities in resource distribution for particular regions and sectors of economy in these regions. From methodological point of view this research shows, that production functions might be used in Development Strategy of SMEs for the period of up to 2030, which establishes double production growth in SMEs. The perspectives for further researches are connected with production functions estimates according to the types of economic activity for building forecasts of SMEs development.

\section{REFERENCES}

Adamadziev, K.R. and, Khalilov, M.A. (2016). Production functions models: the calculation parameters and characteristics, dependency analysis of output from the resource costs. Fundamental researches; 4 (2): 339-345.

Afanasyev, A.A. and Ponomarev, O.S. (2014). Production function of national economy of Russia in 1990-2012. Economics and mathematical methods; 50 (4): 21-33.

Antipov, V.I. (2012). Production function of the Russian economy. Economics, statistics and Informatics; 5: 101-104.

Balistreri, E.J., Mcdaniel, C.A. and Wong, E.V. (2003). An estimation of US industry-level capitallabor substitution elasticities: support for Cobb-Douglas. The North American Journal of Economics and Finance; 14 (3): 343-356.

Baranov, S.V. (2014). Economic models of production functions: history and modernity. Economic Sciences; 10: 53-57.

Baumol, W.J. (2004). Entrepreneurial enterprises, large established firms and other components of the free-market growth machine. Small Business Economics; 23: 9-21.

Belych, T.I. and Burdukovskaja, A.V. (2015). The application of production functions in forecasting. Baikal Research Journal; 6 (4).

Bessonov, V.A. and Tsukhlo, S.V. (2002). Development problems of production functions in the Russian transition economy. Analysis of the dynamics of Russian transition economy. Moscow. Institute of economy in transition: 5-89.

Castano, M.S., Mendez, M.T. and Galindo, M.A. (2016). The effect of public policies on entrepreneurial activity and economic growth. Journal of Business Research; 69(11): 5280-5285.

Charoenrat, T., and Harvie, C. (2013). Technical Efficiency of Thai Manufacturing SMEs: A Stochastic Frontier Analysis. Australasian Accounting. Business and Finance Journal, no. 7(1), pp. 97-122.

Choi, J. and Kim, I. (2017). Regional total factor productivity and local employment growth: evidence from Korea. Asia-Pacific Journal of Regional Science; 1: 1-8.

Demidenko, E.Z. (1981). Linear and nonlinear regression. Moscow: Finance and Statistics: 302.

Doh, S. and Kim, B. (2014). Government support for SME innovations in the regional industries: The case of government financial support program in South Korea. Research Policy; 43 (9): 15571569 . 
Douglas P. (1967). Comments on the Cobb-Douglas Production Function. The Theory and Empirical Analysis of Production. Columbia University Press. pp. 15-22. National Bureau of Economic Research, available at: http://www.nber.org/chapters/c1474. (Accessed December 20, 2017).

Draper, N. and Smith, H. (1998). Applied regression analysis, John Wiley \& Sons, New York, USA.

Eliseeva, I.I. (2003). Econometrics. Moscow: Finance and Statistics: 344.

Federal law, 2007. "On the development of small and medium-sized enterprises in the Russian Federation" from 24.07.2007 No. 209/07-FL.

Federal Statistics Service, 2018. [online] Continuous monitoring of small and medium-sized businesses for the year 2015. Available on http://www.gks.ru/free_doc/new_site/business/prom/ splosh.html (accessed 20.02.2018).

Felipe, J. and McCombie, J. (2012). Problems with Regional Production Functions and Estimates of Agglomeration Economies: A Caveat Emptor for Regional Scientists. Cambridge Centre for Economic and Public Policy. Working Paper no. 725.

Gafarova, E.A. 2013. Modeling of regional development through production functions. Science studies; $3: 1-7$.

Gavrilenkov, E. E. (2000). Economic growth and long-term development strategy of Russia. Russian economy: experience of transformation of the 1990s and prospects for its development. GUVSHE, Moscow, pp. 55-78.

Ginzburg, M. and Pinkovetskaya, Y. (2017). Fiscal capacity of the regions and their SMEs development: evidence from Russia. In Špalková, D., Matějová, L. (Eds): Proceedings of the 21th International Conference: Current Trends in Public Sector Research. Brno: Masaryk University, 148-154.

Granberg, A.G. (1988). Simulation the socialist economy. Moscow: Economics: 487.

Grigore, A.-M.A. and Dragan, I.-M.B. (2015). Entrepreneurship and its economical value in a very dynamic business environment. Amfiteatru Economic; 17 (38): 120-132.

Harris, R. J. (1985). A primer of multivariate statistics. New York: Academic Press: 632.

Kazakova, M.V. (2013). Properties analysis of production functions used in the decomposition of economic growth. Moscow: RANHiGS: 48.

Khodasevich, G. B. [online] Working with experimental data processing on computer. Part 2. Processing one-dimensional arrays. Available on http://dvo.sut.ru/libr/opds/i130hod2/index.htm (accessed 21.12.2017).

Kirilyuk, I.L. (2013). Production functions modeling for the Russian economy. Computer research and modeling; 5 (2): 293-312.

Kleiner, G.B. (1986). Production function: theory, methods, applications. Moscow: Finance and Statistics: 239.

Koo, J.L., Koo, B.L. and Shin, Y.H. (2013). An optimal investment, consumption, leisure, and voluntary retirement problem with Cobb-Douglas utility: Dynamic programming approaches. Applied Mathematics Letters; 26: 481-486.

Labini, P. S. (1995). Why the interpretation of the Cobb-Douglas production function must be radically changed. Structural Change and Economic Dynamics; 6 (4): 485-504.

Mitin, D.V., Ginzburg, M.Y. and Chepyuk, O.R. (2014). Political uncertainty as an economic risk factor. Regional economy: theory and practice; 32 (359): 2-13.

Muro, K. (2013). A note on the three-sector Cobb-Douglas GDP function. Economic Modeling: 31: 18-21.

Pindyck, R. and Rubinfeld, D. (2013). Microeconomics, Pearson, New York, USA.

Pinkovetskaya, Y.S. (2014). Some simulation results of production volumes of business structures. Phase: economic theory, analysis, practice; 2: 107-126.

Ruzanov, A.I. and Ruzanov, P.A. (2015). On new opportunities of economic-mathematical modeling using production functions. Herald of the Nizhny Novgorod University named after N.I. Lobachevsky. Series: Social Sciences; (2): 30-34. 
Vilenskiy, A. (2011). The paradox of small business support: preliminary results of the crisis. Voprosy Ekonomiki; 6: 149-155.

Yashina, N., Ginzburg, M., Emel'yanova, O. and Litovsky, I. (2016). Small and medium enterprise development in Russia: public expenses - are they effective? In Špalková, D., Matějová, L. (Eds): Proceedings of the 20th Scientific Conference: Current Trends in Public Sector Research. Brno: Masaryk University, 215-222. 